\title{
Differential role of MACC1 expression and its regulation of the HGF/c-Met pathway between breast and colorectal cancer
}

\author{
AIKO SUETA $^{1,2}$, YUTAKA YAMAMOTO ${ }^{1,2}$, MUTSUKO YAMAMOTO-IBUSUKI $^{1}$, MITSUHIRO HAYASHI $^{1}$, \\ TAKASHI TAKESHITA $^{1}$, SATOKO YAMAMOTO ${ }^{1}$, YOKO OMOTO $^{1}$ and HIROTAKA IWASE ${ }^{1}$ \\ ${ }^{1}$ Department of Breast and Endocrine Surgery, Kumamoto University Graduate School \\ of Medical Sciences; ${ }^{2}$ Department of Molecular-Targeting Therapy for Breast Cancer, \\ Kumamoto University Hospital, Kumamoto 860-8556, Japan
}

Received December 2, 2014; Accepted January 21, 2015

DOI: $10.3892 /$ ijo.2015.2907

\begin{abstract}
The newly identified gene, metastasis-associated in colon cancer 1 (MACC1), is suggested to be a transcriptional regulator of c-Met, leading to cancer progression in colorectal cancer. To date however, little is known of the role of MACC1 in breast cancer. In a series of 300 breast cancer patients, we analyzed the association of MACC1 mRNA and protein expression with breast cancer survival using Cox proportional hazard models. In an in vitro study, we evaluated activities of c-Met protein after transfection with a MACC1-harboring plasmid as well as the binding ability of MACC1 to the c-Met promoter using a chromatin immunoprecipitation (ChIP) assay. In survival analyses, reduced MACC1 expression was associated with patient mortality. MACC1 expression was an independent prognostic factor in multivariate analysis. In the cell lines tested, MACC1 expression was much higher in colorectal than in breast cancer cells. After cells were transfected with MACC1, c-Met expression was not induced in MCF7 cells, whereas corresponding c-Met expression was upregulated in SW480 cells. Further, SW480 cells transfected with MACC1 showed enhanced migratory ability, whereas in MDA-MB-231 cells, transfection of MACC1 had no impact on this ability. In ChIP assay, the binding of MACC1 to the c-Met promoter was suggested in SW480 cells, but not in MCF7 cells. In conclusion, our findings provide some novel insights into the role of MACC1 in breast cancer, indicating that it plays different roles in breast and several other cancers. There is a possibility that MACC1 does not modulate the transcriptional role of c-Met signaling in breast cancer.
\end{abstract}

Correspondence to: Dr Yutaka Yamamoto, Department of MolecularTargeting Therapy for Breast Cancer, Kumamoto University Hospital, 1-1-1 Honjo, Chuo-ku, Kumamoto 860-8556, Japan

E-mail: ys-yama@triton.ocn.ne.jp

Key words: MACC1, breast cancer, prognosis, c-Met signaling, biomarker

\section{Introduction}

Breast cancer is one of the most common malignancies in women worldwide, including Japan, and its incidence is still increasing (1). Over the past few decades, a great deal of effort has been made to improve the diagnosis and treatment of breast cancer, however, some patients still experience recurrence and clinical progression despite appropriate adjuvant therapy. To identify such patients, many researchers and clinicians have been trying to explore the molecular signaling pathway and gene expression pattern involved in the development of breast cancer, leading to the generation of several prediction tools (2-4). Representative gene sets such as Oncotype DX ${ }^{\circledR}(4)$, MammaPrint $^{\circledR}$ (3), and PAM50 (2) enable us to predict survival in breast cancer patients more accurately than using only established biomarkers, namely, estrogen receptor (ER), progesterone receptor (PR), and human epidermal growth factor receptor 2 (HER2). Additionally, the identification of several novel biomarkers or pathways related to breast cancer has led to the development of molecular therapies targeting these pathways. Among these target therapies are tyrosine kinase inhibitors, agents directed against insulin-like growth factor-1 receptor (IGF-1R), mesenchymal-epithelial transition factor (c-Met) (5) and fibroblast growth factor receptor (FGFR) (6), angiogenesis inhibitors directed against vascular endothelial growth factor (VEGF), and agents that interfere with DNA repair (7). Understanding breast cancer diversity, together with accurate categorization of a patient's subgroup, should allow the effective use of molecular-based targeted therapy.

The metastasis-associated in colon cancer 1 (MACC1), was first identified in primary and metastatic tumors of colon cancer by differential display reverse transcription-polymerase chain reaction (PCR) by Stein et al (8). MACC1 was revealed to be a novel key regulator of tumor growth and metastasis mediated via hepatocyte growth factor (HGF)/c-Met (mesenchymal-epithelial transition factor gene) signaling in colorectal cancers. Increased MACC1 expression has been shown to be correlated with worse survival in several types of cancers, such as colorectal $(8,9)$, hepatocellular $(10)$, gastric $(11)$, and ovarian (12). The HGF/c-Met pathway regulates diverse biological activities, including proliferation, motility, and invasion, 
many of which are hallmarks of cancer development $(13,14)$. Aberrant signaling of the c-Met pathway has been associated with a poor prognosis in various tumors (15-17), including breast cancer (18-20). Stein et al, provided evidence that MACC1 binds to the endogenous c-Met promoter, resulting in increased c-Met transcription and activation of its downstream signaling $(8,21)$.

The significance of MACC1 expression in some cancers has been emphasized, but in human breast cancer it has barely been investigated. We therefore performed comprehensive gene expression analysis of MACC1 in a series of 300 breast cancers to investigate whether MACC1 is a crucial prognostic factor across the cancers. In addition, we evaluated the biological function of MACC1 in regulating c-Met by means of an in vitro study.

\section{Materials and methods}

Subjects and tissues. A total of 300 female patients with primary breast cancer who received both surgery and adjuvant treatment at Kumamoto University Hospital (Kumamoto, Japan) between 2001 and 2009 were selected. Breast cancer tissues were snap-frozen in liquid nitrogen at pretherapeutic biopsy or surgical treatment and stored at $-80^{\circ} \mathrm{C}$ until RNA extraction. Adjuvant and neoadjuvant treatment was assigned to each patient according to their risk on the basis of tumor biology and clinical parameters, also in accordance with the recommendations of the St. Gallen International Expert Consensus on primary therapy of early breast cancer (22); that included $74 \%$ treated with hormonal therapy, $26 \%$ with chemotherapy and $6.8 \%$ with targeted therapy using trastuzumab. Forty-one (13\%) patients did not receive any treatment. Patients received either breast-conserving surgery or total mastectomy and sentinel lymph node biopsy or axillary lymph node dissection. The median follow-up period was 61 months.

Approval for the analyses conducted in the study was received from the Ethics Committee of Kumamoto University Graduate School of Medical Sciences (Kumamoto, Japan). Written informed consent was obtained from all patients.

Immunohistochemical analysis. Histological sections $(4 \mu \mathrm{m})$ were deparaffinized and incubated for $10 \mathrm{~min}$ in methanol containing $0.3 \%$ hydrogen peroxide. They were then immunostained with monoclonal antibodies against ER $\alpha$ (SP1), PR (1E2) (both from Ventana Japan, Tokyo, Japan), HER2 (4B5; Roche Diagnostics K.K., Tokyo, Japan), Ki67 (MIB1; Dako Japan, Kyoto, Japan), and c-Met (D1C2; Cell Signaling Technology Japan K.K., Tokyo, Japan), and a polyclonal antibody against MACC1 (ProSci, Inc., Poway, CA, USA). The staining was carried out in a NexES IHC immunostainer (Ventana Medical Systems, Inc., Tucson, AZ, USA), in accordance with the manufacturer's instructions. ER and PR were regarded as positive if $>1 \%$ of nuclei were stained. HER 2 expression was also determined by IHC staining based on the Hercep test. We considered a tumor to be HER2-positive if the specimen either scored $3+$ by IHC, or showed a $>2.2$-fold increase in fluorescence in situ hybridization (FISH). Tumor subtypes were defined according to the expression of ER, PR and HER2. Ki67 was scored as the percentage of nuclear-stained cells out of all cancer cells in the invasive front of the tumor regardless of the intensity in a x400 high-power field [Ki67 labeling index (23)]. We counted 500-1,000 tumor cells as recommended by the International Ki67 in Breast Cancer Working Group (24). For MACC1 and c-Met expression, the H-score was calculated by multiplying the percentage of positive cells $(0-100)$ by the staining intensity score (0-3).

RNA isolation and quantitative reverse transcription-polymerase chain reaction $(R T-q P C R)$. Total RNA from tissue samples was isolated using the AllPrep ${ }^{\circledR}$ DNA/RNA Mini kit (Qiagen, Valencia, CA, USA) and that from cells was isolated using ReliaPrep ${ }^{\mathrm{TM}}$ RNA Cell Miniprep System (Promega K.K., Tokyo, Japan). RNA was quantified by measuring the A260/A280 absorbance ratios (Nano Drop Technologies, Inc., Wilmington, DE, USA). Total RNA $(0.5 \mu \mathrm{g})$ was reverse transcribed to cDNA using PrimeScript ${ }^{\circledR}$ RT Master Mix (Takara Bio, Inc., Shiga, Japan), according to the manufacturer's instructions. Each quantitative PCR was performed with $2 \mu \mathrm{l}$ of the cDNA and $0.2 \mu \mathrm{mol} / 1$ of each probe in the ABI Prism 7500 (Applied Biosystems, Carlsbad, CA, USA) with SYBR Premix Dimer Eraser (Takara Bio, Inc.). Each reaction (20 $\mu \mathrm{l}$ samples) was performed under the following conditions: initialization for $10 \mathrm{sec}$ at $95^{\circ} \mathrm{C}$, and then 45 cycles of amplification, with $5 \mathrm{sec}$ at $95^{\circ} \mathrm{C}$ for denaturation and $20 \mathrm{sec}$ at $60^{\circ} \mathrm{C}$ for annealing and elongation. The PCR primer sequences are shown in Table I. The expression of target gene was normalized against GAPDH mRNA.

Cell culture. The human breast carcinoma cell line MCF7 was maintained in Eagle's Minimum Essential Medium (EMEM) (Wako Pure Chemical Industries, Ltd., Osaka, Japan), and the cell lines MDA-MB-231, MDA-MB-468, and SW480 were maintained in Dulbecco's modified Eagle's medium (DMEM) (Gibco, Grand Island, NY, USA), and T47D, MDA-MB-453, and DLD-1 cells were maintained in RPMI-1640 medium (Gibco). All media were supplemented with $10 \%$ fetal bovine serum (SAFC Biosciences, Inc., Lenexa, KS, USA) and all cell lines were maintained at $37^{\circ} \mathrm{C}$ in an incubator with $5 \% \mathrm{CO}_{2}$.

Cell motility and proliferation assay. Cell migration was estimated by scratch motility assay. Aliquots of $20 \times 10^{4}$ cells were seeded into wells of 6-well plate and grown overnight to confluence. After $24 \mathrm{~h}$, transfection was performed, and after another $24 \mathrm{~h}$, the monolayer was scratched with a pipette tip, then washed with PBS to remove floating cells. The number of cells that migrated into the scratched area was photographed on days 0-3. Cell proliferation was determined using Cell Counting kit-8 (Dojindo Laboratories, Kumamoto, Japan). WST- 8 reagent solution $(10 \mu \mathrm{l})$ was added to each well, then the microplate was incubated for $2 \mathrm{~h}$ in an incubator at $37^{\circ} \mathrm{C}$. Absorbance at $450 \mathrm{~nm}$ was then measured using an EMax Precision Microplate Reader (Molecular Devices Japan K.K., Tokyo, Japan). Each experimental group contained three replicate wells, and the experiment was repeated three times.

Generating of plasmid DNA containing the MACC1 ORF. Plasmid DNA containing the MACC1 ORF was generated using the Flexi ${ }^{\circledR}$ Vector System (http://www.promega. com/tbs/tm254/tm254.html). Full-length human MACC1 was transferred from pFN21AE2447 to pFN28K HaloTag ${ }^{\circledR}$ 
Table I. Oligonucleotide sequences for PCR, siRNA, and ChIP.

Sequence $\left(5^{\prime} \rightarrow 3^{\prime}\right)$

\begin{tabular}{ll}
\hline RT-qPCR & \\
MACC1 & F: TTCTTTTGATTCCTCCGGTGA \\
& R: ACTCTGATGGGCATGTGCTG \\
c-Met & F: GAGAAGCCCAAGCCCATCC \\
& R: GCCCAGGGCTCAGAGCTT \\
HGF & F: GAATGACACTGATGTTCCTTTGG \\
& R: GGATACTGAGAATCCCAACGC \\
GAPDH & F: GCACCGTCAAGGCTGAGAAC \\
& R: ATGGTGGTGAAGACGCCAGT
\end{tabular}

siRNA

$\begin{array}{ll}\text { MACC1-1 } & \text { F: AGGUAAGAUUGGACUUGUAtt } \\ & \text { R: UACAAGUCCAAUCUUACCUct } \\ \text { MACC1-2 } & \text { F: AGUUAGUACGACUCACAAAtt } \\ & \text { R: UUUGUGAGUCGUACUAACUtt } \\ \text { Control } & \text { F: UUCUCCGAACGUGUCACGUdTdT } \\ & \text { R: ACGUGACACGUUCGGAGAAdTdT }\end{array}$

ChIP

c-Met promoter F: CTAACTTCAGACTGCCTGAGC R: CACCACCCAGAGGGAAATC

PCR, polymerase chain reaction; siRNA, small interference RNA; ChIP, chromatin immunoprecipitation; RT-qPCR, quantitative reverse transcription-polymerase chain reaction; MACC1, metastasis-associated in colon cancer 1; F, forward; R, reverse; HGF, hepatocyte growth factor.

CMV-neo Flexi ${ }^{\circledR}$ Vector (both from Promega K.K.), using Sgf I and Pme. A control vector harboring only HaloTag was constructed using pFN28K HaloTag ${ }^{\circledR}$ CMV-neo Flexi ${ }^{\circledR}$ Vector (Promega K.K.). We generated some mutations in the Barnase coding region of the vector using the PrimeSTAR ${ }^{\circledR}$ Mutagenesis Basal kit (Takara Bio, Inc.) to abolish the function of the Barnase gene. E. coli DH5 $\alpha$ competent cells (Takara Bio, Inc.) were used for transformation according to the manufacturer's instructions. Plasmid purification was performed using a HiSpeed ${ }^{\text {TM }}$ Plasmid Maxi kit (Qiagen). We confirmed expression of each protein by western blotting and performed immunofluorescence assays to evaluate the transfection efficacy.

Transfections and treatments. Transfections into MDA-MB231 and SW480 cells were carried out using FuGENE ${ }^{\circledR}$ HD (Promega K.K.) according to the manufacturer's instructions. MCF7 cells were transfected using a NEPA21 Electroporator (Nepa Gene Co., Ltd., Chiba, Japan) according to the manufacturer's instructions. The transfected cells were cultured for $48 \mathrm{~h}$ before harvesting total RNA or protein.

MACC1 siRNA and control siRNA (both from Qiagen) were transfected into the cells with a cocktail of $20 \mathrm{nM}$ each using Lipofectamine ${ }^{\mathrm{TM}}$ RNAiMAX (Life Technologies Japan, Tokyo, Japan) according to the manufacturer's instructions.
These sequences are described in Table I. For expression analysis, cells were harvested $48 \mathrm{~h}$ after siRNA transfection.

Cell cultures were treated with HGF (Sigma, St. Louis, $\mathrm{MO}, \mathrm{USA}$ ) at $20 \mathrm{ng} / \mathrm{ml}$ for $24 \mathrm{~h}$.

Protein extraction and western blotting. Cultured cells were washed in ice-cold PBS and lysed in Mammalian Protein Extraction Buffer (GE Healthcare Ltd., Buckinghamshire, UK). The protein concentration was determined using a Pierce Protein 660 nm Protein Assay (Thermo Fisher Scientific K.K., Kanagawa, Japan). Equal amounts of protein were separated on Mini-PROTEAN ${ }^{\circledR}$ TGX $^{\mathrm{TM}}$ gel and electrophoretically transferred onto Trans-Blot ${ }^{\circledR}$ Turbo $^{\mathrm{TM}}$ Mini Nitrocellulose membranes (both from Bio-Rad Laboratories, Inc., Hercules, CA, USA). The membranes were blocked and incubated overnight at $4^{\circ} \mathrm{C}$ with primary antibody; anti-MACC1 (1:200; Santa Cruz Biotechnology, Inc., Santa Cruz, CA, USA), anti-c-Met $(1: 1,000)$, anti- $\beta$-actin $(1: 500)$ (both from Cell Signaling Technology Japan K.K.) or anti-HaloTag ${ }^{\circledR}$ (1:1,000; Promega K.K.). Proteins were visualized with horseradish peroxidase-conjugated secondary antibodies (anti-rabbit IgG, HRP-linked antibody, Cell Signaling Technology Japan K.K.; anti-goat IgG-HRP, Santa Cruz Biotechnology, Inc.) followed by chemiluminescence detection (Pierce Western Blotting Substrate Plus; Thermo Fisher Scientific K.K.).

Chromatin immunoprecipitation (ChIP). Immunoprecipitation was performed using the HaloCHIP ${ }^{\mathrm{TM}}$ System, which is an antibody-free alternative to the ChIP method that utilizes the HaloTag ${ }^{\circledR}$ fusion protein (25). The detailed protocol can be found at: http://www.promega.com/tbs/tm075/tm075.html. Briefly, $24 \mathrm{~h}$ before transfection, the cells were seeded and allowed to attach, then transfections with HaloTag ${ }^{\circledR}$-MACC1 fusion constructs and control vector were performed as described above. Forty-eight hours after transfection, the cells were crosslinked with formaldehyde (Sigma-Aldrich Japan K.K., Tokyo, Japan) at a final concentration of $1 \%$ and quenched with $0.125 \mathrm{M}$ glycine. Chromatin was sheared by sonication using a Bioruptor ${ }^{\circledR}$ (Cosmo Bio Co., Ltd., Tokyo, Japan), and the HaloTag ${ }^{\circledR}-\mathrm{MACC} 1$ fusion protein and DNA complex was captured by incubation with HaloLink ${ }^{\mathrm{TM}}$ Resin for $2 \mathrm{~h}$ at room temperature. This allows complete covalent linkage between the resin, protein and DNA. Subsequently, DNA was released by reversal of crosslinking for 6-8 h at $65^{\circ} \mathrm{C}$. Isolated DNA was further purified using a QIAquick PCR Purification kit (Qiagen) and amplified using AmpliTaq Gold $^{\circledR} 360$ Master Mix (Life Technologies Japan). It has been shown that c-Met is a transcriptional target of MACC1 in colorectal cancer, we therefore generated a c-Met primer whose amplicon included an Sp1-1 site in the c-Met promoter, where MACC1 might bind. The primer sequences of c-Met promoter are shown in Table I.

Statistical analysis. Comparisons between two groups were performed by two-sided Student's t-test. The significance of differences in categorized demographic variables as a result of MACC1 expression was evaluated using the Chi-square or Fisher's exact test, and the non-parametric Mann-Whitney U test. Relapse-free survival (RFS) and breast cancer-specific survival (BCSS) curves were generated using the Kaplan-Meier 
A
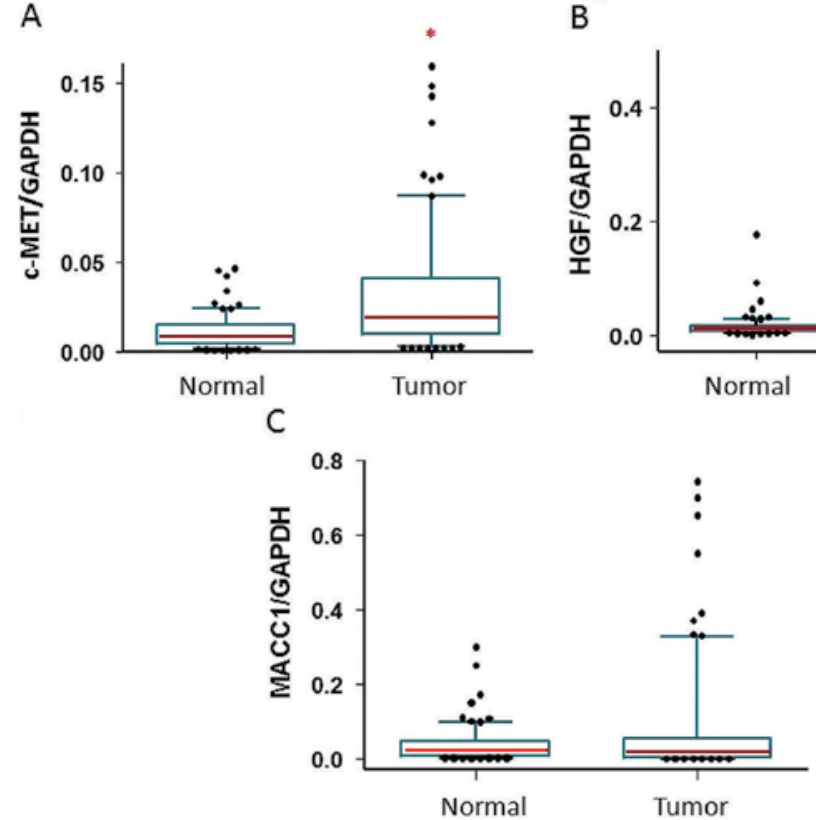

B

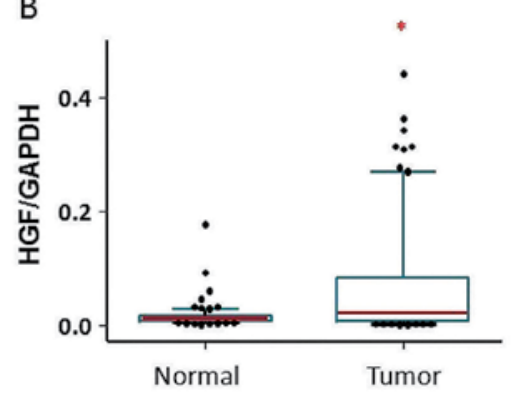

Figure 1. mRNA expression in normal and breast cancer tissues ( $\mathrm{n}=172)$. Target gene expression was normalized against GAPDH mRNA. (A) c-Met, (B) hepatocyte growth factor (HGF), (C) metastasis-associated in colon cancer 1 (MACC1) mRNA expression.

A MACC1 negative (H-score $<50) \quad$ B $\quad$ MACC1 positive $(\mathrm{H}$-score $\geq 50)$

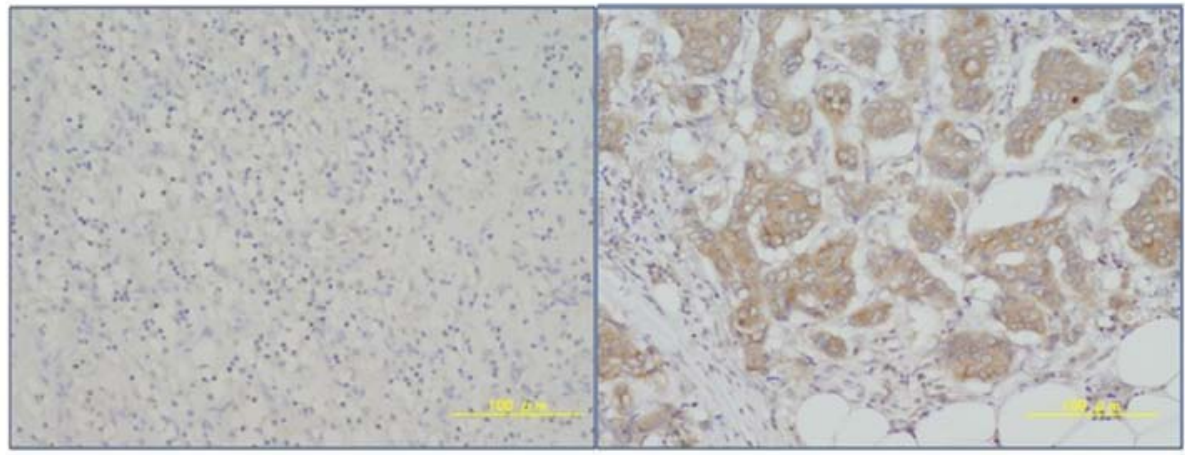

Figure 2. Representative images of the metastasis-associated in colon cancer 1 (MACC1) immunostaining in breast cancer tissue samples (magnification, $\mathrm{x} 100$ ). When the H-score cut-off point was set at $50,71 \%$ of the patients exhibited high levels of MACC1 expression.

method and verified by the Wilcoxon test. Cox's proportional hazards model was used for univariate and multivariate analyses of survival. All statistical analyses were carried out using STATA ver.12 (StataCorp LP, College Station, TX, USA). All tests were two-sided and $\mathrm{P}<0.05$ was considered statistically significant.

\section{Results}

Reduced MACCl expression in breast cancer is associated with worse prognosis. We first compared the expression levels of MACC1, c-Met, and HGF mRNA in breast cancers and normal breast tissues ( $n=172$, Fig. 1). Expression of both c-Met and HGF was higher in malignant tissues than in normal tissues (each Wilcoxon $\mathrm{P}<0.001$ ), whereas there was no difference in MACC1 expression between them.

In a series of 300 breast cancer patients, MACC1 expression was analyzed by IHC and RT-qPCR. We calculated the cut-off points for the corresponding expressions using a ROC curve analysis. The IHC analysis showed that MACC1 staining was detectable mainly in the cytoplasm and that $71 \%$ of the patients exhibited high levels of MACC1 expression in their tumor samples when the H-score cut-off point was set at 50 (Fig. 2). In this analysis, correlation between MACC1 mRNA and protein expressions was weak (Spearman's $\gamma=0.25, \mathrm{P}<0.001)$. For the survival analysis, 43 patients $(14 \%)$ experienced recurrence and 27 patients $(8.9 \%)$ died as a result of breast cancer during a median follow-up period of 61 months. As shown in Fig. 3, the patients with low levels of MACC1 (both mRNA and protein) were more likely to have reduced RFS and BCSS compared to those with higher levels. In multivariate analysis using a Cox proportional hazard model, MACC1 mRNA (HR=0.25, $\mathrm{P}=0.001)$, MACC1 protein $(\mathrm{HR}=0.37, \mathrm{P}=0.016)$, axillary nodal status $(\mathrm{HR}=5.09$, $\mathrm{P}=0.003)$, and $\mathrm{ER}$ status $(\mathrm{HR}=0.09, \mathrm{P}<0.001)$ were independent predictors of mortality (Table II). 
A

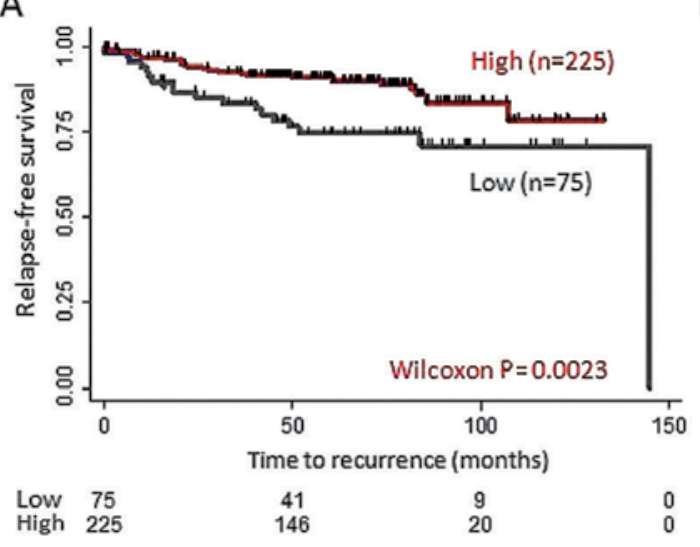

C

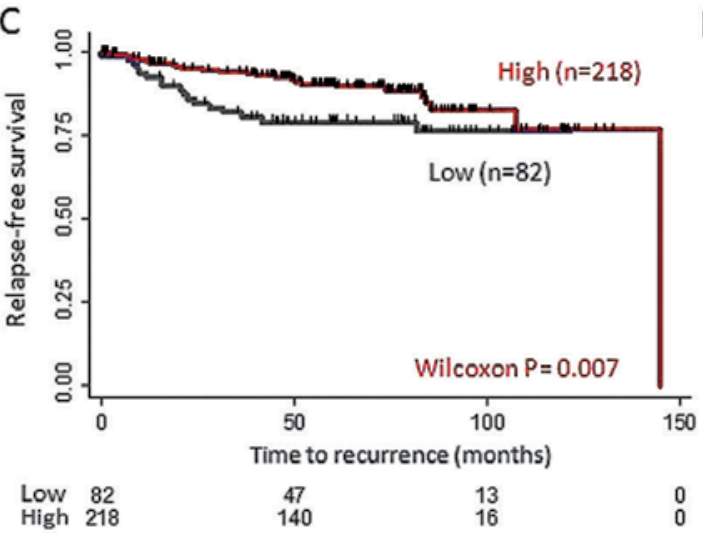

B

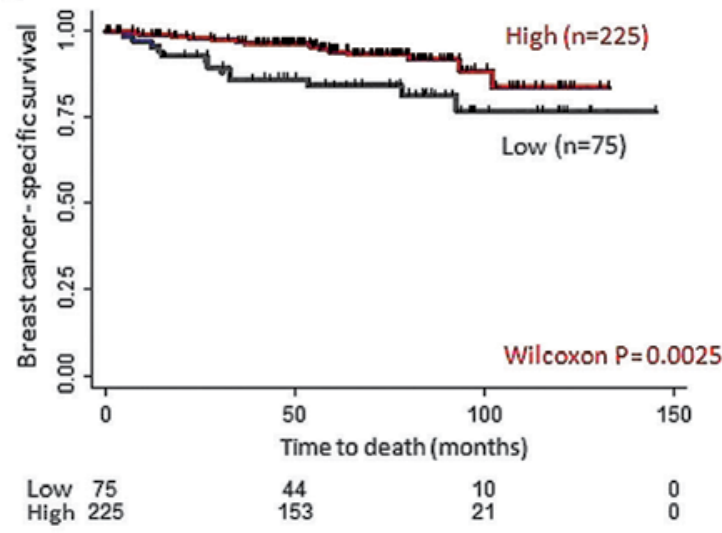

D

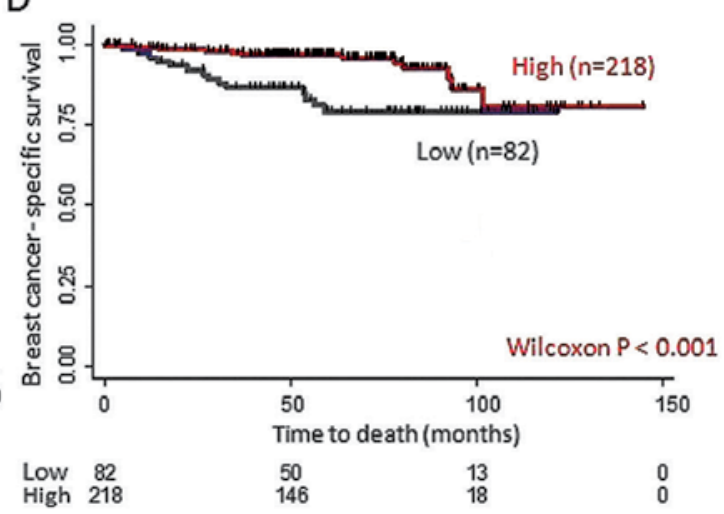

Figure 3. Kaplan-Meier analyses of relapse-free survival (RFS) and breast cancer-specific survival (BCSS) in relation to the metastasis-associated in colon cancer 1 (MACC1) expression. Survivals in relation to MACC1 (A and B) mRNA expression and (C and D) protein expression.

Table II. Univariate and multivariate analysis for BCSS (Cox proportional hazard model).

\begin{tabular}{|c|c|c|c|c|}
\hline \multirow[b]{2}{*}{ Variable } & \multicolumn{2}{|c|}{ Univariate analysis } & \multicolumn{2}{|c|}{ Multivariate analysis } \\
\hline & $\mathrm{HR}(95 \% \mathrm{CI})$ & $\mathrm{P}$ & $\mathrm{HR}(95 \% \mathrm{CI})$ & $\mathrm{P}$ \\
\hline \multicolumn{5}{|l|}{ Tumor size } \\
\hline$>2 \mathrm{~cm}$ vs. $\leq 2 \mathrm{~cm}$ & $2.92(1.23-6.92)$ & 0.015 & $1.44(0.50-4.14)$ & 0.495 \\
\hline \multicolumn{5}{|l|}{ Axillary lymph node } \\
\hline Positive vs. negative & $3.39(1.48-7.76)$ & 0.004 & $5.09(1.74-14.8)$ & 0.003 \\
\hline \multicolumn{5}{|l|}{ Nuclear grade } \\
\hline G2-3 vs. G1 & $2.45(1.06-5.64)$ & 0.035 & $0.80(0.29-2.18)$ & 0.656 \\
\hline \multicolumn{5}{|l|}{ Ki67 labeling index (\%) } \\
\hline$\geq 15$ vs. $<15$ & $5.29(1.25-22.4)$ & 0.024 & $2.40(0.55-10.6)$ & 0.245 \\
\hline \multicolumn{5}{|l|}{ ER status } \\
\hline Positive vs. negative & $0.11(0.05-0.25)$ & $<0.001$ & $0.09(0.03-0.26)$ & $<0.001$ \\
\hline \multicolumn{5}{|l|}{ PR status } \\
\hline Positive vs. negative & $0.14(0.06-0.36)$ & $<0.001$ & & \\
\hline \multicolumn{5}{|l|}{ HER2 status } \\
\hline Positive vs. negative & $0.91(0.31-2.63)$ & 0.856 & & \\
\hline \multicolumn{5}{|l|}{ MACC 1 expression } \\
\hline mRNA high vs. low & $0.42(0.19-0.89)$ & 0.024 & $0.25(0.11-0.58)$ & 0.001 \\
\hline Protein high vs. low & $0.37(0.17-0.79)$ & 0.011 & $0.37(0.16-0.83)$ & 0.016 \\
\hline
\end{tabular}

BCSS, breast cancer-specific survival; CI, confidence interval; ER, estrogen receptor; PR, progesterone receptor; HER2, human epidermal growth factor receptor 2; MACC1, metastasis-associated in colon cancer 1 . 
Table III. Correlations between MACC1 expression and clinicopathological characteristics.

\begin{tabular}{|c|c|c|c|c|c|}
\hline & $\begin{array}{l}\text { No. of } \\
\text { patients }\end{array}$ & $\begin{array}{l}\text { MACC1 mRNA } \\
\text { Low/high (\%) }\end{array}$ & $\mathrm{P}^{\mathrm{a}}$ & $\begin{array}{c}\text { MACC1 protein } \\
\text { Low/high }(\%)\end{array}$ & $\mathrm{P}^{\mathrm{a}}$ \\
\hline No. & & $76 / 228(75)$ & & $82 / 218(73)$ & \\
\hline \multicolumn{6}{|l|}{ Age } \\
\hline$<50$ & 71 & $13 / 58(82)$ & \multirow[t]{2}{*}{0.136} & $18 / 53(75)$ & \multirow[t]{2}{*}{0.438} \\
\hline$\geq 50$ & 229 & $62 / 167(73)$ & & $69 / 160(70)$ & \\
\hline \multicolumn{6}{|l|}{ Menopausal status } \\
\hline Pre- & 79 & $16 / 63(80)$ & \multirow[t]{2}{*}{0.196} & 23/56 (71) & \multirow[t]{2}{*}{0.997} \\
\hline Post- & 220 & $59 / 161(73)$ & & $64 / 156(71)$ & \\
\hline \multicolumn{6}{|l|}{ Tumor size } \\
\hline$\leq 2 \mathrm{~cm}$ & 152 & $42 / 110(72)$ & \multirow[t]{2}{*}{0.286} & 44/108 (71) & \multirow[t]{2}{*}{0.984} \\
\hline$>2 \mathrm{~cm}$ & 148 & $33 / 115(78)$ & & $43 / 105(71)$ & \\
\hline \multicolumn{6}{|l|}{ Nodal status } \\
\hline Negative & 179 & $41 / 138(77)$ & \multirow[t]{2}{*}{0.308} & $56 / 123(69)$ & \multirow[t]{2}{*}{0.289} \\
\hline Positive & 121 & $34 / 87(72)$ & & $31 / 90(74)$ & \\
\hline \multicolumn{6}{|l|}{ Stage } \\
\hline I & 111 & 28/83 (75) & \multirow[t]{3}{*}{0.777} & $33 / 78(70)$ & \multirow[t]{3}{*}{0.819} \\
\hline II & 159 & $38 / 121(76)$ & & $47 / 112(70)$ & \\
\hline III & 30 & 9/21 (70) & & 7/23 (77) & \\
\hline \multicolumn{6}{|l|}{ Nuclear grade } \\
\hline 1 & 152 & $38 / 114(75)$ & \multirow[t]{3}{*}{0.386} & $51 / 101(66)$ & \multirow[t]{3}{*}{0.149} \\
\hline 2 & 74 & $15 / 59(80)$ & & $16 / 58(78)$ & \\
\hline 3 & 73 & $22 / 51(70)$ & & $19 / 54(74)$ & \\
\hline \multicolumn{6}{|l|}{ ER status } \\
\hline Negative & 68 & 17/51 (75) & \multirow[t]{2}{*}{1.00} & $22 / 46(68)$ & \multirow[t]{2}{*}{0.488} \\
\hline Positive $(\geq 1 \%)$ & 232 & $58 / 174(75)$ & & 65/167 (72) & \\
\hline \multicolumn{6}{|l|}{ PR status } \\
\hline Negative & 101 & $31 / 70(69)$ & \multirow[t]{2}{*}{0.105} & $34 / 67(66)$ & \multirow[t]{2}{*}{0.205} \\
\hline Positive $(\geq 1 \%)$ & 199 & $44 / 155(78)$ & & $53 / 146(73)$ & \\
\hline \multicolumn{6}{|l|}{ HER2 status } \\
\hline Negative & 257 & 67/190 (74) & \multirow[t]{2}{*}{0.295} & 76/181 (70) & \multirow[t]{2}{*}{0.594} \\
\hline Positive & 43 & $8 / 35(81)$ & & $11 / 32(74)$ & \\
\hline Ki67 labeling ind & & & & & \\
\hline$<15 \%$ & 95 & 22/73 (77) & 0.616 & $33 / 62(65)$ & 0.136 \\
\hline$\geq 15 \%$ & 205 & $53 / 152(74)$ & & $54 / 151(74)$ & \\
\hline Tumor subtype & & & & & \\
\hline Luminal & 219 & $52 / 167(76)$ & 0.096 & $59 / 160(73)$ & 0.072 \\
\hline Luminal-HER2 & 14 & $4 / 10(71)$ & & $5 / 9(64)$ & \\
\hline HER2-rich & 29 & $4 / 25(86)$ & & $6 / 23(79)$ & \\
\hline Triple-negative & 38 & $15 / 23(61)$ & & $17 / 21(55)$ & \\
\hline
\end{tabular}

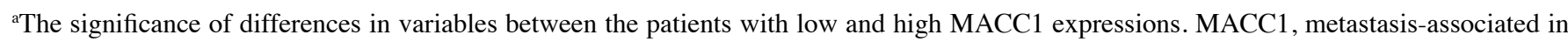
colon cancer 1; ER, estrogen receptor; PR, progesterone receptor; HER2, human epidermal growth factor receptor 2.

Relationship between MACC1 expression and other clinicopathological factors. We also examined the correlation between MACC1 expression and clinicopathological factors, but no significant correlations were found (Table III). We further evaluated the correlation between MACC1 protein and c-Met mRNA expressions based on the findings that MACC1 is a transcriptional regulator of c-Met in colorectal cancer. We found no strong positive correlation between them, with a Spearman's coefficient of $0.16(\mathrm{P}=0.0067)$.

MACCl and c-Met are differentially expressed in breast and colorectal cancer cell lines. Next, we evaluated the level of 
A

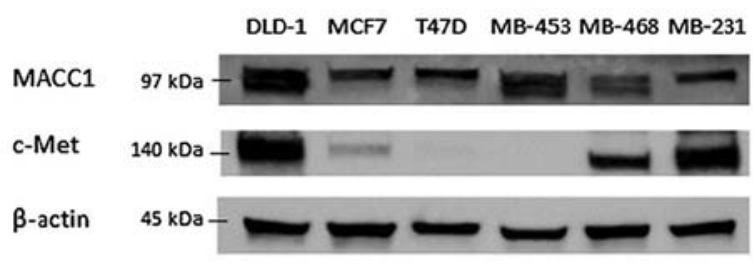

B

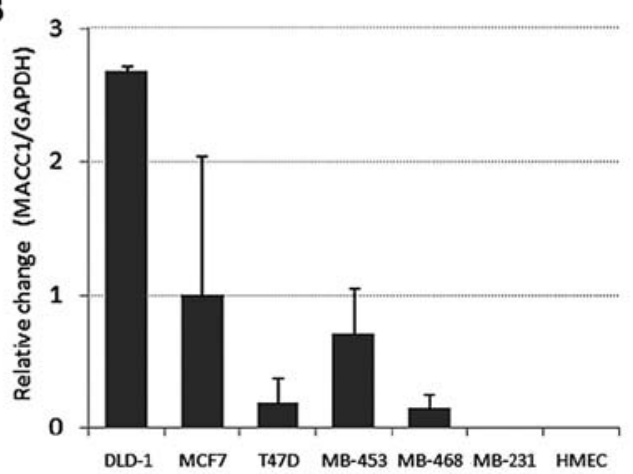

Figure 4. Analysis of the metastasis-associated in colon cancer 1 (MACC1) expression in colon cancer cells and in several breast cancer cell lines. (A) MACC1 expression in one colon cancer cell line (DLD-1) and five breast cancer cell lines (MCF7, T47D, MDA-MB-453, MDA-MB-468 and MDA-MB-231) by western blotting. (B) MACC1 mRNA expression in the corresponding cell lines and in HMEC, which is a non-malignant mammary epithelial cell line.

A
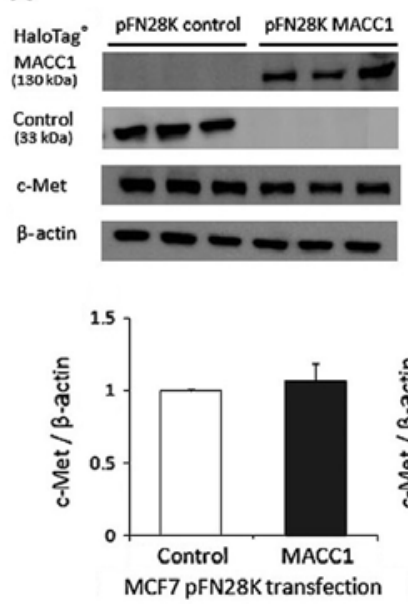

B

pFN28K control pFN28K MACC1
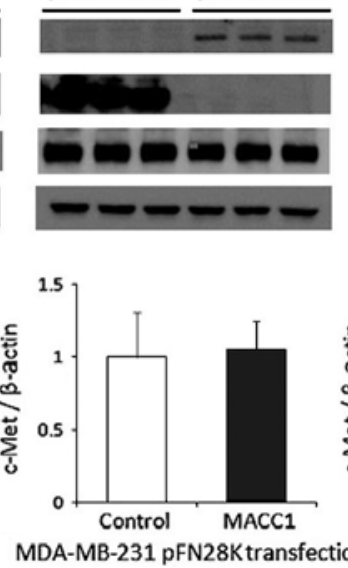

C

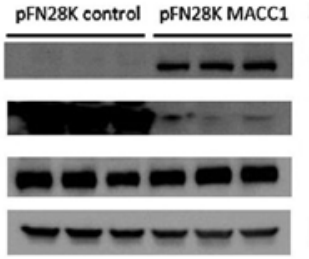

D
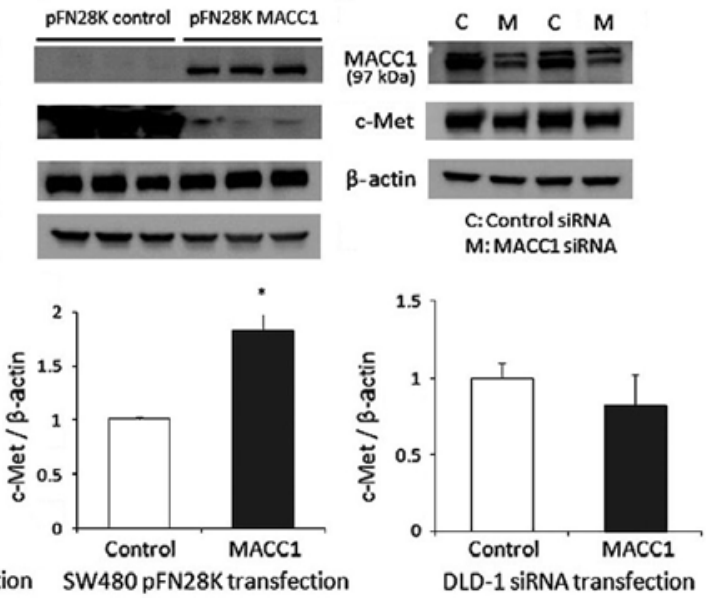

Figure 5. Changes in c-Met protein expression after transfection with (A-C) pFN28K HaloTag ${ }^{\circledR}$ metastasis-associated in colon cancer 1 (MACC1) or (D) MACC1 siRNA. pFN28K control expressed HaloTag ${ }^{\circledR}$ protein only. (A) MCF7, (B) MDA-MB-231, (C) SW480, (D) DLD-1. "P<0.05 vs. control groups.

MACC1 expression in colon cancer and several breast cancer cell lines by western blotting and RT-qPCR analyses (Fig. 4). MACC1 expression was much higher in DLD-1 colon cancer cells than in any of the breast cancer cell lines. Further, we found differences in its expression among breast cancer cell lines; luminal-type cell lines including MCF7 and T47D had lower levels of MACC1 protein than HER2-type (MDA-MB-453) or triple-negative-type cell lines (MDA-MB-468). c-Met expression, in DLD-1, MDA-MB-231, and MDA-MB-468 cell lines exhibited high levels.

MACCl overexpression does not influence the expression of c-Met protein in breast cancer cell lines. To evaluate the impact of MACC1 on the biological function of the cells, we transfected MACC1 constructs (pFN28K HaloTag ${ }^{\circledR}$ MACC1 and pFN28K HaloTag ${ }^{\circledR}$ control) into the MCF7, MDA-MB-231, and SW480 cells which normally do not express endogenous MACC1. As shown in Fig. 5, a significant increase in c-Met expression was found only in SW480 cells transfected with MACC1 for $48 \mathrm{~h}$ (Fig. 5C). There was no significant difference in MCF7 or MDA-MB-231 cells (Fig. 5A and B). In the colon cancer cell line DLD-1 which exhibited high expression of
MACC1, c-Met expression was suppressed in the cells transfected with MACC1 siRNA for $48 \mathrm{~h}$ (Fig. 5D).

Moreover, we evaluated the effect of MACC1 expression on the migratory and proliferative potential of the transfected cells. MACC1 overexpression had no impact on the proliferative ability of either breast or colon cancer cells (data not shown). In contrast, SW480 cells transfected with pFN28K MACC1 showed enhanced migratory ability compared to that of pFN28K control-transfected cells (Fig. 6B), whereas in MDA-MB-231 cells, transfection of MACC1 had no impact on this ability (Fig. 6A).

HGF induction of $c$-Met expression is not enhanced in breast cancer cells transfected with MACC1. Since it was previously reported that $\mathrm{HGF}$, which is a ligand of c-Met, induces translocation of MACC1 from the cytoplasm to the nucleus in SW480 cells, leading to the activation of c-Met signaling (8), we compared the HGF-induced c-Met expression in MCF7 and SW480 cells transfected with MACC1. As shown in Fig. 7, the SW480 cells transfected with pFN28K MACC1 expressed more c-Met protein after HGF treatment compared to the controls transfected with $\mathrm{pFN} 28 \mathrm{~K}$. In contrast, transfection of 
A

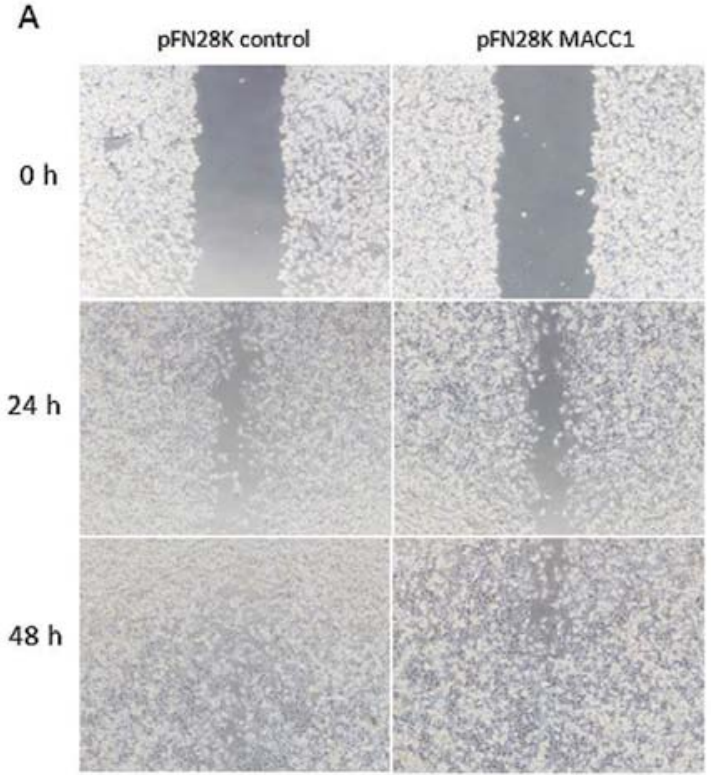

MDA-MB-231
B

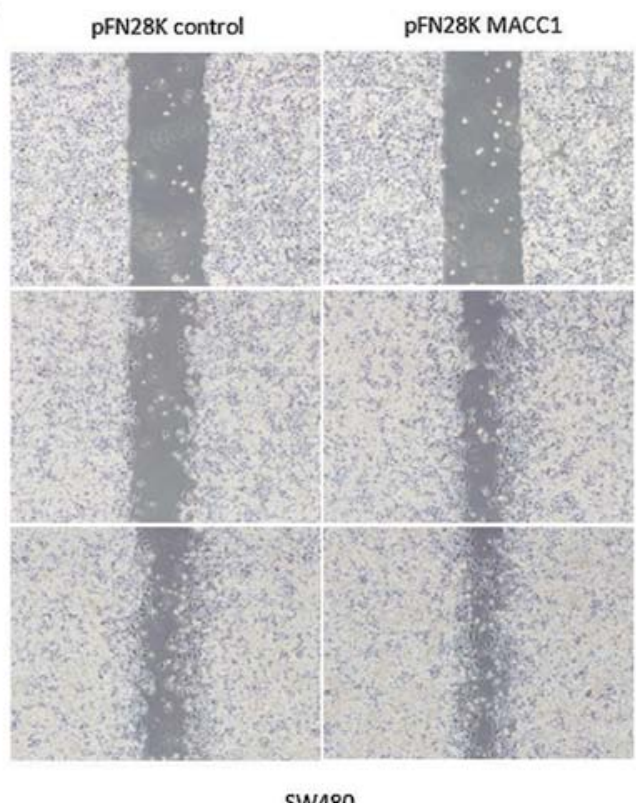

SW480

Figure 6. Evaluation of cell migration by scratch motility assay in (A) MDA-MB-231 and (B) SW480 cells. Cell migration was promoted in SW480 cells expressing metastasis-associated in colon cancer 1 (MACC1).
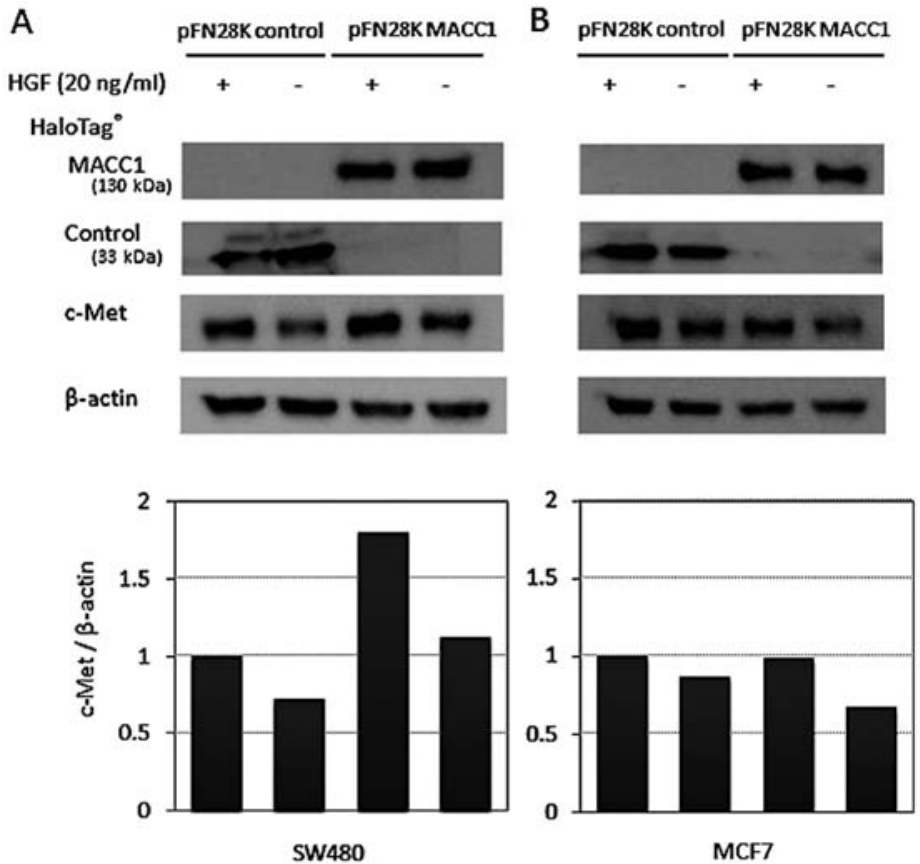

Figure 7. Hepatocyte growth factor (HGF)-induced c-Met expression in (A) SW480 and (B) MCF7 cells transfected with pFN28K. Cells were treated with HGF at $20 \mathrm{ng} / \mathrm{ml}$ for $24 \mathrm{~h}$. HGF-induced c-Met expression was enhanced by metastasis-associated in colon cancer 1 (MACC1) overexpression only in SW480 cells.

the corresponding MCF7 cells with MACC1 had no impact on the effect of HGF-induced c-Met expression. This indicates that the MACC1-HGF/c-Met loop has different roles in breast and colorectal cancers.

MACC1 does not bind to the c-Met promoter region in breast cancer cell lines. It was previously demonstrated that MACC1 specifically binds to the SP1 site of the c-Met promoter to activate the c-Met signaling cascade in SW480 cells (21).
Based on this finding, we performed the ChIP analysis using the HaloCHIP ${ }^{\mathrm{TM}}$ System (described in Materials and methods) to confirm that MACC1 binds to the c-Met promoter in all the cell lines tested (Fig. 8). A visible band on amplification of immune precipitated chromatin for the c-Met promoter was found in SW480 cells transfected with MACC1, whereas no signal bands were detected in MCF7 cells. This suggests that MACC1 binds to the c-Met promoter region in SW480 cells, but not in MCF7 cells. 
MCF7

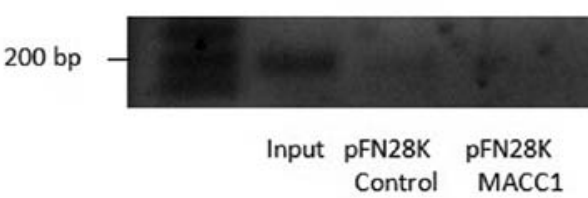

SW480

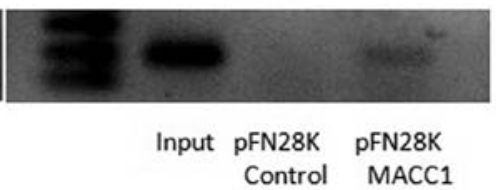

Figure 8. HaloChIP analysis of the metastasis-associated in colon cancer 1 (MACC1) binding to the c-Met promoter region in MCF7 and SW480 cells A visible band was detected in SW480 after pFN28K MACC1 transfection, but not in MCF7.

\section{Discussion}

The results of this study provide additional evidence regarding the role of MACC1, indicating that it plays different roles in breast cancer and in several other cancers. In the present study, MACC1 expression was associated with prolonged RFS and BCSS in breast cancer patients, which was beyond our expectation and not in agreement with previous studies $(8,10-12)$. Additionally, our in vitro studies suggest that MACC1 may not regulate c-Met expression in breast cancer cells, a theory which was also given support by the finding that MACC1 did not bind to the c-Met promoter in MCF7 cells when analyzed by ChIP. Further, MACC1 overexpression did not have a functional impact on cell migration or proliferation abilities in breast cancer cells. Consequently MACC1 appears not to contribute to disease progression in breast cancer via $\mathrm{HGF} / \mathrm{c}-$ Met signaling.

$M A C C 1$ was first identified as a colon cancer oncogene which promoted metastasis, and to date, a few studies have demonstrated its role in several cancers (8-11). However, little is known about its role in breast cancer, except for one report by Huang et al (26). The results of their study, suggesting that MACC1 may be an independent prognostic indicator of a worse outcome is inconsistent with our findings. Possible reasons for these discordant findings could be the differences in selection of the patient cohort and in determination of adjuvant treatment. In our study, the majority of the patients received some adjuvant treatment, including the use of endocrine, chemotherapy, and trastuzumab therapy; only 41 (13\%) patients did not receive any treatment. In contrast, in the study by Huang et al, most of the patients $(56.2 \%)$ received no endocrine treatment although information of regarding other treatment was not available (26). There is the possibility that the effect of adjuvant treatment modified the prognostic role of MACC1 expression. To date, many biomarkers have been investigated and proposed as prognostic markers, nevertheless, only a small proportion of those ultimately proved clinically useful. This may partly be due to insufficient validation or conflicting results across the studies. For example, IGF-1R has been identified as an adverse prognostic factor for breast cancer in some studies $(27,28)$, whereas others report the favorable prognostic role of IGF-1R $(29,30)$. Thus, evidence for the potential role of MACC1 as a biomarker in breast cancer will need to be accumulated from further studies in other large cohort.

Our results reveal that patients with low levels of MACC1 are more likely to have a worse prognosis compared to those with higher levels, when analyzed using an optimally-estimated cut-off point (Fig. 3). The biological mechanism of MACC1 which underlies improvement of breast cancer prognosis remains unelucidated in the present study. Our results suggest that MACC1 expression is intrinsically low in breast cancer based on the following findings. Our in vitro studies show that MACC1 protein expression in breast cancer cells, especially in luminal-type cells, is generally lower than that in colon cancer cells (DLD-1) (Fig. 4). Additionally, a comprehensive analysis of gene expression indicates differences in MACC1 expression levels in a variety of human tissues (31). According to the database, the highest MACC1 expression was observed in colorectal carcinoma, followed by stomach, gastrointestinal, pancreatic, and ovarian carcinoma, and its expression in breast cancer was much lower than in these carcinomas (32). These differences in the levels of endogenous MACC1 expression might be attributable to differences in physiological function between breast cancer and several other types of cancers.

We further investigated the regulatory effect of MACC1 on c-Met expression in cell lines, and demonstrated that c-Met expression was not induced after MACC1 transfection in breast cancer cell lines, a finding that differed from the results observed in colon cancer cells (Fig. 5). MACC1 siRNA treatment of MDA-MB-468 cells, in which MACC1 expression was relatively high, also revealed no alteration of c-Met expression (data not shown). c-Met is a proto-oncogene considered essential for conferring metastatic potential in various tumors $(14,15,33,34)$. c-Met activates its downstream effectors of the Ras-mitogen-activated protein kinase (MAPK) and phosphatidylinositol 3-kinase (PI3K)-Akt pathways to promote the invasive growth characteristic of malignancies $(35,36)$. Also in breast cancer, disruption of the c-Met pathway has been shown to contribute to worse prognosis $(20,37)$ and confer resistance to endocrine therapy or trastuzumab treatment (38-40). In addition to c-Met, its ligand HGF is also suggested to be an independent prognostic parameter for breast cancer $(41,42)$. Hence, it was of great interest to us to understand the significance of MACC1 as a candidate regulator of the HGF/c-Met cascade in breast cancer. A previous study has suggested the hypothesis of a MACC1-driven positive feedback loop after its binding to the c-Met promoter and subsequent activation of c-Met signaling (43). In our study, HGF-induced c-Met expression was not enhanced by MACC1 transfection in MCF7 cells in contrast to the effect in SW480 cells (Fig. 7), indicating uncertainty of this feedback mechanism in breast cancer. Since c-Met transcription appears to be activated by several factors besides MACC1, such as hypoxia-inducible factor 1 (HIF1) and AP-1 $(34,44)$, it is possible that MACC1 does not act as the exclusive master regulator of the $\mathrm{HGF} / \mathrm{c}-\mathrm{Met}$ signaling involved in disease progression in breast cancer. 
The MACCl gene is located on human chromosome 7 (7p21.1) and consists of seven exons and six introns. The MACC1 protein harbors an Src homology 3 (SH3) domain, ZU5 domain, and two death domains (DD) (31). Protein-protein interactions involving MACC1 are possible based on its domain structure (45). Further, MACC1 binds to the SP1 domain, which is found within the promoter regions of numerous genes (46). Accordingly, MACC1 could act as a transcriptional factor for a hitherto unknown target or interact with other proteins leading to improved outcomes for patients with breast cancer. Comprehensive analyses such as ChIP-seq analysis or mass spectrometry are therefore required to confirm this hypothesis.

In conclusion, our study reveals that MACC 1 expression is associated with prolonged RFS and BCSS, and demonstrates that its prognostic impact is independent of established prognostic factors. In breast cancer cells, our findings suggest that $\mathrm{MACC} 1$ is not a major regulator of the transcriptional target gene, c-Met. Although MACC1 has been suggested to be a crucial marker related to cancer development in colorectal cancer, its role in breast cancer appears to differ. Further evidence for any potential role of MACC1 as a biomarker in breast cancer should be accumulated.

\section{Acknowledgements}

The authors are grateful to Y. Azakami for excellent technical support, to A. Okabe for clinical data management, to Dr M. Nakano (Department of Molecular Genetics, Kumamoto University) for providing breast cancer cell lines and technical support, and to Dr K. Kuwahara (Department of Immunology, Kumamoto University) for providing the SW480 cell line. This study was supported by a Grant in Aid for Scientific Research from the Ministry of Education, Culture, Sports, Science and Technology of Japan (Y. Yamamoto, Grant no. 24591909).

\section{References}

1. Matsuda T, Marugame T, Kamo K, Katanoda K, Ajiki W and Sobue T; Japan Cancer Surveillance Research Group: Cancer incidence and incidence rates in Japan in 2005: based on data from 12 population-based cancer registries in the Monitoring of Cancer Incidence in Japan (MCIJ) project. Jpn J Clin Oncol 41: 139-147, 2011.

2. Parker JS, Mullins M, Cheang MC, et al: Supervised risk predictor of breast cancer based on intrinsic subtypes. J Clin Oncol 27: 1160-1167, 2009.

3. van't Veer LJ, Dai H, van de Vijver MJ, et al: Gene expression profiling predicts clinical outcome of breast cancer. Nature 415 : 530-536, 2002

4. Cronin M, Sangli C, Liu ML, Pho M, Dutta D, Nguyen A, Jeong J, $\mathrm{Wu}$ J, Langone $\mathrm{KC}$ and Watson D: Analytical validation of the Oncotype DX genomic diagnostic test for recurrence prognosis and therapeutic response prediction in node-negative, estrogen receptor-positive breast cancer. Clin Chem 53: 1084-1091, 2007.

5. Sierra JR and Tsao MS: c-MET as a potential therapeutic target and biomarker in cancer. Ther Adv Med Oncol 3 (Suppl 1): S21-S35, 2011.

6. Turner N, Lambros MB, Horlings HM, et al: Integrative molecular profiling of triple negative breast cancers identifies amplicon drivers and potential therapeutic targets. Oncogene 29 : 2013-2023, 2010.

7. Turner N, Tutt A and Ashworth A: Hallmarks of 'BRCAness' in sporadic cancers. Nat Rev Cancer 4: 814-819, 2004.

8. Stein U, Walther W, Arlt F, Schwabe H, Smith J, Fichtner I, Birchmeier W and Schlag PM: MACC1, a newly identified key regulator of HGF-MET signaling, predicts colon cancer metastasis. Nat Med 15: 59-67, 2009.
9. Boardman LA: Overexpression of MACC1 leads to downstream activation of $\mathrm{HGF} / \mathrm{MET}$ and potentiates metastasis and recurrence of colorectal cancer. Genome Med 1: 36, 2009.

10. Qiu J, Huang P, Liu Q, Hong J, Li B, Lu C, Wang L, Wang J and Yuan Y: Identification of MACC1 as a novel prognostic marker in hepatocellular carcinoma. J Transl Med 9: 166, 2011.

11. Wang L, Wu Y, Lin L, et al: Metastasis-associated in colon cancer-1 upregulation predicts a poor prognosis of gastric cancer, and promotes tumor cell proliferation and invasion. Int J Cancer 133: 1419-1430, 2013.

12. Zhang R, Shi H, Chen Z, Wu Q, Ren F and Huang H: Effects of metastasis-associated in colon cancer 1 inhibition by small hairpin RNA on ovarian carcinoma OVCAR-3 cells. J Exp Clin Cancer Res 30: 83, 2011.

13. Maulik G, Shrikhande A, Kijima T, Ma PC, Morrison PT and Salgia R: Role of the hepatocyte growth factor receptor, c-Met, in oncogenesis and potential for therapeutic inhibition. Cytokine Growth Factor Rev 13: 41-59, 2002.

14. Bottaro DP, Rubin JS, Faletto DL, Chan AM, Kmiecik TE, Vande Woude GF and Aaronson SA: Identification of the hepatocyte growth factor receptor as the c-met proto-oncogene product. Science 251: 802-804, 1991.

15. Di Renzo MF, Olivero M, Giacomini A, et al: Overexpression and amplification of the met/HGF receptor gene during the progression of colorectal cancer. Clin Cancer Res 1: 147-154, 1995.

16. Humphrey PA, Zhu X, Zarnegar R, Swanson PE, Ratliff TL, Vollmer RT and Day ML: Hepatocyte growth factor and its receptor (c-MET) in prostatic carcinoma. Am J Pathol 147: 386-396, 1995 .

17. Amemiya H, Kono K, Itakura J, Tang RF, Takahashi A, An FQ, Kamei S, Iizuka H, Fujii $\mathrm{H}$ and Matsumoto Y: c-Met expression in gastric cancer with liver metastasis. Oncology 63: 286-296, 2002 .

18. Jin L, Fuchs A, Schnitt SJ, Yao Y, Joseph A, Lamszus K, Park M, Goldberg ID and Rosen EM: Expression of scatter factor and c-met receptor in benign and malignant breast tissue. Cancer 79: 749-760, 1997.

19. Camp RL, Rimm EB and Rimm DL: Met expression is associated with poor outcome in patients with axillary lymph node negative breast carcinoma. Cancer 86: 2259-2265, 1999.

20. Lengyel E, Prechtel D, Resau JH, et al: C-Met overexpression in node-positive breast cancer identifies patients with poor clinical outcome independent of Her2/neu. Int J Cancer 113: 678-682, 2005.

21. Stein U, Smith J, Walther W and Arlt F: MACC1 controls Met: what a difference an Sp1 site makes. Cell Cycle 8: 2467-2469, 2009.

22. Goldhirsch A, Wood WC, Coates AS, Gelber RD, Thürlimann B and Senn HJ; Panel members: Strategies for subtypes - dealing with the diversity of breast cancer: highlights of the St. Gallen International Expert Consensus on the Primary Therapy of Early Breast Cancer 2011. Ann Oncol 22: 1736-1747, 2011.

23. Yamamoto S, Ibusuki M, Yamamoto Y, Fu P, Fujiwara S, Murakami K and Iwase H: Clinical relevance of Ki67 gene expression analysis using formalin-fixed paraffin-embedded breast cancer specimens. Breast Cancer 20: 262-270, 2013.

24. Dowsett M, Nielsen TO, A'Hern R, et al; International Ki-67 in Breast Cancer Working Group: Assessment of Ki67 in breast cancer: recommendations from the International Ki67 in Breast Cancer working group. J Natl Cancer Inst 103: 1656-1664, 2011.

25. Hartzell DD, Trinklein ND, Mendez J, Murphy N, Aldred SF, Wood $\mathrm{K}$ and Urh M: A functional analysis of the CREB signaling pathway using HaloCHIP-chip and high throughput reporter assays. BMC Genomics 10: 497, 2009.

26. Huang Y, Zhang H, Cai J, Fang L, Wu J, Ye C, Zhu X and Li M: Overexpression of MACC1 and its significance in human breast cancer progression. Cell Biosci 3: 16, 2013.

27. Law JH, Habibi G, Hu K, et al: Phosphorylated insulin-like growth factor-i/insulin receptor is present in all breast cancer subtypes and is related to poor survival. Cancer Res 68: 10238-10246, 2008.

28. Railo MJ, von Smitten K and Pekonen F: The prognostic value of insulin-like growth factor-I in breast cancer patients. Results of a follow-up study on 126 patients. Eur J Cancer 30A: 307-311, 1994.

29. Shin A, Ren Z, Shu XO, Cai Q, Gao YT and Zheng W: Expression patterns of insulin-like growth factor 1 (IGF-I) and its receptor in mammary tissues and their associations with breast cancer survival. Breast Cancer Res Treat 105: 55-61, 2007. 
30. Papa V, Gliozzo B, Clark GM, McGuire WL, Moore D, Fujita-Yamaguchi Y, Vigneri R, Goldfine ID and Pezzino V: Insulin-like growth factor-I receptors are overexpressed and predict a low risk in human breast cancer. Cancer Res 53: 3736-3740, 1993.

31. Stein U, Dahlmann M and Walther W: MACC1 - more than metastasis? Facts and predictions about a novel gene. J Mol Med Berl 88: 11-18, 2010

32. http://www.ncbi.nlm.nih.gov/UniGene/ESTProfileViewer.cgi? uglist=Hs. 598388

33. Kang JY, Dolled-Filhart M, Ocal IT, Singh B, Lin CY, Dickson RB, Rimm DL and Camp RL: Tissue microarray analysis of hepatocyte growth factor/Met pathway components reveals a role for Met, matriptase, and hepatocyte growth factor activator inhibitor 1 in the progression of node-negative breast cancer. Cancer Res 63: 1101-1105, 2003.

34. Boccaccio $\mathrm{C}$ and Comoglio PM: Invasive growth: A MET-driven genetic programme for cancer and stem cells. Nat Rev Cancer 6 637-645, 2006.

35. Peschard $\mathrm{P}$ and Park M: From Tpr-Met to Met, tumorigenesis and tubes. Oncogene 26: 1276-1285, 2007

36. Trusolino L, Bertotti A and Comoglio PM: MET signalling: Principles and functions in development, organ regeneration and cancer. Nat Rev Mol Cell Biol 11: 834-848, 2010.

37. Ghoussoub RA, Dillon DA, D'Aquila T, Rimm EB, Fearon ER and Rimm DL: Expression of c-met is a strong independent prognostic factor in breast carcinoma. Cancer 82: 1513-1520, 1998.

38. Hiscox S, Jordan NJ, Jiang W, Harper M, McClelland R, Smith C and Nicholson RI: Chronic exposure to fulvestrant promotes overexpression of the c-Met receptor in breast cancer cells: Implications for tumour-stroma interactions. Endocr Relat Cancer 13: 1085-1099, 2006.
39. Shattuck DL, Miller JK, Carraway KL III and Sweeney C: Met receptor contributes to trastuzumab resistance of Her2-overexpressing breast cancer cells. Cancer Res 68: 1471-1477, 2008.

40. Minuti G, Cappuzzo F, Duchnowska R, et al: Increased MET and HGF gene copy numbers are associated with trastuzumab failure in HER2-positive metastatic breast cancer. Br J Cancer 107: 793-799, 2012.

41. Jiang WG, Martin TA, Parr C, Davies G, Matsumoto K and Nakamura T: Hepatocyte growth factor, its receptor, and their potential value in cancer therapies. Crit Rev Oncol Hematol 53: 35-69, 2005.

42. Maemura M, Iino Y, Yokoe T, Horiguchi J, Takei H, Koibuchi Y, Horii Y, Takeyoshi I, Ohwada S and Morishita Y: Serum concentration of hepatocyte growth factor in patients with metastatic breast cancer. Cancer Lett 126: 215-220, 1998.

43. Arlt F and Stein U: Colon cancer metastasis: MACC1 and Met as metastatic pacemakers. Int J Biochem Cell Biol 41: 2356-2359, 2009.

44. Pennacchietti S, Michieli P, Galluzzo M, Mazzone M, Giordano S and Comoglio PM: Hypoxia promotes invasive growth by transcriptional activation of the met protooncogene. Cancer Cell 3 347-361, 2003.

45. Ipsaro JJ, Huang L and Mondragón A: Structures of the spectrin-ankyrin interaction binding domains. Blood 113: 5385-5393, 2009.

46. Kadonaga JT, Jones KA and Tjian R: Promoter-specific activation of RNA polymerase II transcription by $\mathrm{Sp} 1$. Trends Biochem Sci 11: 20-23, 1986. 